\section{PLUTAČA KAO POMAGALO U PODUCI OSNOVNIH ELEMENATA JEDRENJA}

\section{SAŽETAK}

Cilj istraživanja je utvrditi učinkovitost plutača kao metodičkog pomagala u poduci $i$ učenju osnovnih elemenata jedrenja. Analizirane elemente jedrenja činili su prihvaćanje, letanje, otpadanje $i$ kruženje na tri različite jedriličarske pozicije (kormilo, glavno jedro iflok).

Istraživanje je provedeno na uzorku od 178 studenata Kineziološkog fakulteta koji su bili podijeljeni u dvije grupe (kontrolna i eksperimentalna). Ispitanici eksperimentalne grupe bili su podvrgnuti poduci uz pomoć različitih poligona plutača dok su ispitanici kontrolne grupe bili podvrgnuti klasičnoj poduci (bez primjene poligona plutača). Proces poučavanja proveden je u trajanju od 7 dana na jedrilicama tipa Elan 19. Rezultati deskriptivne statistike ukazuju na višse ocjene ispitanika kod eksperimentalne grupe gotovo u svim elementima jedriličarske tehnike osim kod elementa letanje-flok. Jednosmjerna analiza varijance pokazala je da su te razlike značajne na poziciji kormilar u elementima prihvaćanje, otpadanje i kruženje, poziciji glavno jedro, element prihvaćanje te poziciji flok također element prihvaćanje. U daljnjoj analizi diskriminacijska analiza potvrdila je značajnu razliku po količini usvojenog znanja jedriličarske tehnike između dviju analiziranih grupa $\left(\chi^{2}=\right.$ 47,73, $p=0,00)$. Na temelju dobivenih rezultata autori zaključuju da poligon plutača značajno utječe na količinu usvojenog znanja jedriličarskih vještina.

Ključne riječi: poligon plutača, metode poučavanja, jedriličar, škola jedrenja, početnik 


\section{UVOD}

U posljednja dva desetljeća interes prema jedrenju i njegova popularnost sve više raste (Neville i Folland, 2009; Bøymo-Having, Grävare i Silbernagel, 2013), tako da danas postoje stotine jedriličarskih klasa (Allen i De Jong, 2006), a u jedrenju uživa preko 16 milijuna ljudi (Neville i Folland, 2009) bilo u rekreacijskom ili natjecateljskom smislu.

Stalni razvoj nautičkog turizma, otvaranje sve većeg broja škola jedrenja, te sve veći broj organiziranja velikih natjecateljskih manifestacija u jedrenju, zahtijevaju kvalitetniji stručni jedriličarski kadar. Osim toga, sve brži način života uvjetuje sve kraći boravak gostiju, pa je nužno prilagođavati programe škole jedrenja i njihovim potrebama. Upravo iz navedenih razloga očekuje se od poligona plutača da će ubrzati, a samim time i uvećati kvalitetu poduke.

Poligon plutača danas predstavlja svakodnevnicu u poduci rekreativaca, natjecatelja, djece itd. Pa tako Oreb (2000) govori o „Hodniku plutača“ kao pomagalu koje s organizacijskog aspekta omogućuje izuzetnu kontrolu jedriličara, prostornu definiranost, sigurnost kretanja jedriličara u odnosu na njih same i u odnosu na ostale jedrilice. Također, s metodičkog aspekta, plutače predstavlja kao orijentir po kojima jedriličar može shvatiti, doživjeti i realizirati elemente poput prihvaćanja, letanja, otpadanja i kruženja. Osim navedenog zaključuje kako takvi poligoni zadovoljavaju u smislu igre, situacijskog ponašanja i usavršavanja tehnike. White i Wells (1995) navode čitav niz primjera poligona kao mogućih načina u poduci natjecatelja.

Kada se govori o poligonu plutača, nije teško prepoznati mnoge prednosti koje nam donosi takva vrsta pomagala, odnosno igraonice, prilikom poduke jedriličarskih vještina. Međutim, u praksi se nailazi na pitanja koja se postavljaju vezana uz stvarnu isplativost poligona plutača. Pa je tako očit problem nedostatka vremena potrebnog za postavljanje takvih poligona, posebno u područjima u kojima su dubine nerijetko i do $150 \mathrm{~m}$. Upravo takvi problemi naveli su autore da provedu istraživanje kako bi se došlo do saznanja kada i koliko stvarno poligoni plutača doprinose usvajanju jedriličarskih vještina.

\section{METODE}

Istraživanje je provedeno na uzorku od 178 studenata Kineziološkog fakulteta Sveučilišta u Zagrebu, koji su slučajnim odabirom podijeljeni u kontrolnu $(n=86)$ i eksperimentalnu $(\mathrm{n}=92)$ grupu. Temeljni uvjet koji su ispitanici trebali zadovoljiti kako bi postali dio uzorka je da prije istraživanja nisu jedrili.

Za utvrđivanje razine stečenog znanja jedriličarskih vještina odabrana su četiri osnovna elementa tehnike (prihvaćanje, letanje, otpadanje, kruženje) na tri radna mjesta (kormilo, glavno jedro, flok) u jedrilici tipa Elan 19.

Elementi su bili procijenjeni na osnovu video zapisa kojim je zabilježena demonstracija ispitanika u navedenim elementima. Procjenu naučenih specifičnih motoričkih znanja u području jedrenja izvršila su tri educirana ocjenjivača s dugogodišnjim iskustvom u procjenjivanju znanja iz jedrenja. Ocjenjivači su bili prethodno instruirani o kriterijima procjene svakog elementa. Svi ocjenjivači procjenu su izvršili istovremeno i tom su prilikom bili međusobno nezavisni. Znanje jedrenja u ovom je istraživanju procijenjeno ocjenama od 15, a rezultati ocjenjivanja izraženi su na Likertovoj skali od pet stupnjeva koja pripada ordinalnoj mjernoj skali (Mejovšek, 2003 prema Supek,1981). Elementi koje su ispitanici učili sastavni su dio svake jedriličarske škole u svijetu te se istovremeno nalaze i u programu redovitog studija Kineziološkog fakulteta Sveučilišta u Zagrebu.

S ciljem provedbe planiranog istraživanja, proveden je eksperiment u trajanju od četiri tjedna u Badijskom akvatoriju (Korčula), dok je sam proces poučavanja pojedinog studenata trajao sedam dana (Tablica 1). Ispitanici eksperimentalne grupe bili su podvrgnuti poduci uz

Prlenda, N., Oreb, I., \& Vujčić, D. (2018). Plutača kao pomagalo u poduci osnovnih elemenata jedrenja. Sportlogia, 14 (1), 47-55. doi: 10.5550/sgia.181401.se.pov 
pomoć različitih poligona plutača dok su ispitanici kontrolne grupe bili podvrgnuti klasičnoj poduci (bez primjene poligona plutača).

Bitan čimbenik u provedbi istraživanja bio je izbor ispitanika s jednakim predznanjem jedrenja, te osiguravanjem jednakih uvjeta prilikom poduke. Tako je u obje grupe poduka i kasnije procjena jedriličarskih elemenata provedena na jednakim plovilima (jedrilica Elan19) $\mathrm{u}$ istom akvatoriju, te su svi ispitanici imali optimalne vjetrovne uvjete (između 4 i 6 čvorova), more mirno do malo valovito.

Tablica 1 Plan poduke i učenja elemenata tehnike jedrenja

\begin{tabular}{|c|c|c|}
\hline \multirow{2}{*}{$\begin{array}{l}\text { Tijek } \\
\text { podučavanja }\end{array}$} & \multicolumn{2}{|c|}{ Distribucija elemenata jedriličarske tehnike po danima } \\
\hline & Eksperimentalna grupa & Kontrolna grupa \\
\hline \multirow[t]{3}{*}{ 1.Dan } & $\begin{array}{c}\text { Osnovne informacije o jedrilici i samoj } \\
\text { opremi }\end{array}$ & $\begin{array}{l}\text { Osnovne informacije o jedrilici i } \\
\text { samoj opremi }\end{array}$ \\
\hline & $\begin{array}{c}\text { Jedriličarske pozicije i kretanje po } \\
\text { brodu }\end{array}$ & $\begin{array}{l}\text { Jedriličarske pozicije i kretanje } \\
\text { po brodu }\end{array}$ \\
\hline & Podizanje jedara & Podizanje jedara \\
\hline \multirow[t]{2}{*}{ 2. Dan } & Ugađanje jedara & Jedrenje bočnim vjetrom \\
\hline & $\begin{array}{l}\text { Jedrenje bočnim vjetrom u koridoru } \\
\text { plutača }\end{array}$ & Ugađanje jedara \\
\hline \multirow[t]{3}{*}{ 3. Dan } & Prihvaćanje & \multirow{2}{*}{ Prihvaćanje } \\
\hline & Otpadanje & \\
\hline & $\begin{array}{c}\text { Prihvaćanje i otpadanje u koridoru } \\
\text { plutača }\end{array}$ & Otpadanje \\
\hline \multirow[t]{3}{*}{ 4. Dan } & Maksimalno prihvaćanje & \multirow{2}{*}{ Maksimalno prihvaćanje } \\
\hline & Maksimalno otpadanje & \\
\hline & $\begin{array}{l}\text { Maksimalno prihvaćanje i otpadanje u } \\
\text { koridoru plutača }\end{array}$ & Maksimalno otpadanje \\
\hline \multirow[t]{2}{*}{ 5. Dan } & Letanje & \multirow[t]{2}{*}{ Letanje } \\
\hline & Letanje u koridoru plutača & \\
\hline \multirow[t]{2}{*}{ 6. Dan } & Kruženje & \multirow[t]{2}{*}{ Kruženje } \\
\hline & Kruženje u koridoru plutača & \\
\hline \multirow[t]{2}{*}{ 7. Dan } & Ponavljanje & Ponavljanje \\
\hline & Ocjenjivanje & Ocjenjivanje \\
\hline
\end{tabular}

Svi dobiveni podaci obrađeni su pomoću statističkog paketa za obradu podataka „SPSS for Windows 15.0“. Za svaku grupu (eksperimentalnu i kontrolnu) zasebno izračunati su osnovni statistički parametri: aritmetička sredina i standardna devijacija. Diskriminativnom analizom utvrđeno je postojanje značajne razlike između eksperimentalne i kontrolne grupe $\mathrm{u}$ poduci i učenju elemenata tehnike jedrenja različitim metodičkim postupcima. Također je pomoću jednosmjerne analize varijance (Anova) utvrđena značajnost razlike između eksperimentalne i kontrolne grupe za svaku kriterijsku varijablu zasebno.

Prlenda, N., Oreb, I., \& Vujčić, D. (2018). Plutača kao pomagalo u poduci osnovnih elemenata jedrenja. Sportlogia, 14 (1), 47-55. doi: 10.5550/sgia.181401.se.pov 


\section{REZULTATI}

Kao što je već opisano, tri suca su ocjenjivala razinu usvojenog znanja studenata na dvanaest elemenata tehnike u jedrenju. Njihova objektivnost utvrđena je na osnovu korelacije između dodijeljenih ocjena na pojedinom elementu tehnike (od $r=64$ do $r=94$ ), a pomoću faktorske analize utvrđeno je da je njihov predmet mjerenja visoko suglasan $\mathrm{i}$ da oni promatraju i ocjenjuju istu stvar, što je omogućilo da se u nastavku promatra prosječna ocjena sva tri suca na pojedinom elementu tehnike.

U Tablici 2. prikazani su rezultati deskriptivne statistike (aritmetička sredina i standardna devijacija) za obje grupe ispitanika i rezultati jednosmjerne analize varijance.

Tablica 2 Deskriptivni pokazatelji obje grupe ispitanika i rezultati jednosmjerne analize varijance

\begin{tabular}{|c|cccccc|}
\hline Jedriličarski elementi & $\begin{array}{c}\text { Eksperimentalna } \\
\text { grupa } \\
\text { (poligon } \\
\text { plutača) }\end{array}$ & \multicolumn{2}{c}{$\begin{array}{c}\text { Kontrolna } \\
\text { grupa }\end{array}$} & ANOVA \\
& M & SD & M & SD & F & p \\
\hline $\begin{array}{c}\text { prihvaćanje-kormilo } \\
\text { (PK) }\end{array}$ & 3,77 & 0,79 & 3,40 & 0,70 & 10,61 & 0,00 \\
prihvaćanje-glavno & & & & & & \\
jedro (PG) & 3,87 & 0,72 & 3,48 & 0,61 & 14,89 & 0,00 \\
prihvaćanje-flok (PF) & 3,69 & 0,67 & 3,46 & 0,72 & 5,07 & 0,03 \\
letanje-kormilo (LK) & 3,59 & 0,76 & 3,39 & 0,87 & 2,65 & 0,11 \\
letanje-glavno jedro & & & & & & \\
(LG) & 3,73 & 0,73 & 3,63 & 0,71 & 0,87 & 0,35 \\
letanje-flok (LF) & 3,57 & 0,77 & 3,63 & 0,74 & 0,27 & 0,60 \\
otpadanje-kormilo & & & & & & \\
(OK) & 3,67 & 0,69 & 3,39 & 0,67 & 7,65 & 0,01 \\
otpadanje-glavno jedro & & & & & & \\
(OG) & 3,74 & 0,69 & 3,61 & 0,71 & 1,44 & 0,23 \\
otpadanje-flok (OF) & 3,60 & 0,64 & 3,50 & 0,68 & 1,15 & 0,28 \\
kruženje-kormilo (KK) & 3,65 & 0,75 & 3,31 & 0,77 & 8,94 & 0,00 \\
kruženje-glavno jedro & & & & & & \\
(KG) & 3,66 & 0,80 & 3,50 & 0,66 & 2,29 & 0,13 \\
kruženje-flok (KF) & 3,58 & 0,65 & 3,57 & 0,70 & 0,02 & 0,89 \\
\hline
\end{tabular}

Vidljivo je kako su aritmetičke sredine ocjena ispitanika više kod ispitanika eksperimentalne grupe u svim elementima jedriličarske tehnike osim kod elementa letanjeflok. Kod eksperimentalne grupe najniže ocjene postignute su u elementu letanje i kruženje na poziciji floka $(3,57$ i 3,58$)$,a najviše prosječne ocjene na elementu prihvaćanje na poziciji glavnog jedra i kormila $(3.87,3.77)$, dok je kod kontrolne grupe situacija obrnuta, pa su najniže ocjene dodijeljene na poziciji kormilara u svim jedriličarskim elementima (KK-3,31, OK-3,39, LK-3,39, PK-3,40, ) dok su viši prosjeci postignuti na pozicijama flokiste i glavnog jedra (LG-3,63 i LF-3.63). Najveće razlike u aritmetičkim sredinama prisutne su kod elemenata prihvaćanje - glavno jedro (0.39), prihvaćanje - kormilo (0.37) i kruženje - kormilo $(0,34)$, dok su najmanje razlike prisutne kod kruženja - flok $(0.01)$, letanje - flok (-0.06) i

Prlenda, N., Oreb, I., \& Vujčić, D. (2018). Plutača kao pomagalo u poduci osnovnih elemenata jedrenja. Sportlogia, 14 (1), 47-55. doi: 10.5550/sgia.181401.se.pov 
otpadanje - flok (0.10). Rezultati jednosmjerne analize varijance ukazuju na postojanje značajne razlike u primijenjenim modelima, na poziciji kormilar u elementima prihvaćanje, otpadanje i kruženje, poziciji glavno jedro na elementu prihvaćanje, te poziciji flok na elementu prihvaćanje u korist eksperimentalne grupe. Diskriminacijskom analizom utvrđena je značajnost razlika u izvedbi jedriličarske tehnike između kontrolne i eksperimentalne grupe. To pokazuje razina značajnosti $\chi 2$ testa (p) koja je manja od 0,01 (Tablica 3).

Tablica 3 Rezultati diskriminacijske funkcije između eksperimentalne i kontrolne grupe

\begin{tabular}{|cccccc|}
\hline$\lambda$ & $\mathrm{Rc}$ & $\mathrm{w} \lambda$ & $\chi^{2}$ & $\mathrm{df}$ & $\mathrm{p}$ \\
\hline 0,32 & 0,49 & 0,76 & 47,73 & 12 & 0,00 \\
\hline
\end{tabular}

$\lambda$ - svojstvena vrijednost, Rc - kanonička korelacija, w $\lambda$ - Wilksowa lambda, $\chi^{2-}$ vrijednosti hi-kvadrat testa, df - broj stupnjeva slobode, $\mathrm{p}$ - razina značajnosti diskriminacijske funkcije

U Tablici 4. možemo naći korelacije varijabli sa diskriminativnom funkcijom, dok se u Tablici 5. nalaze pozicije centroida eksperimentalne i kontrolne grupe na diskriminativnoj funkciji.

Tablica 4 Korelacija varijabli s diskriminacijskom funkcijom

\begin{tabular}{|c|c|}
\hline Varijable & \\
\hline prihvaćanje-glavno jedro & 0,51 \\
prihvaćanje-kormilo & 0,43 \\
kruženje-kormilo & 0,40 \\
otpadanje-kormilo & 0,37 \\
prihvaćanje-flok & 0,30 \\
letanje-kormilo & 0,22 \\
kruženje-glavno jedro & 0,20 \\
otpadanje-glavno jedro & 0,16 \\
otpadanje-flok & 0,14 \\
letanje-glavno jedro & 0,12 \\
letanje-flok & $-0,07$ \\
kruženje-flok & 0,02 \\
\hline
\end{tabular}

Tablica 5 Položaj centroida grupa na diskriminacijskoj funkciji

\begin{tabular}{|cc|}
\hline $\begin{array}{c}\text { Položaj centroida } \\
\text { eksperimentalne(1) } \\
\text { i kontrolne } \\
\text { grupe(2) }\end{array}$ \\
\hline 1 & 0,55 \\
2 & $-0,59$ \\
\hline
\end{tabular}

Prlenda, N., Oreb, I., \& Vujčić, D. (2018). Plutača kao pomagalo u poduci osnovnih elemenata jedrenja. Sportlogia, 14 (1), 47-55. doi: 10.5550/sgia.181401.se.pov 
Ispitanici kontrolne grupe se nalaze na negativnom polu diskriminativne funkcije i imaju vrijednost $-0,59$, dok je prosječni rezultat eksperimentalne grupe na pozitivnom polu $(0,55)$. Struktura diskriminativne funkcije je također bipolarna. Prema korelacijama varijabli s diskriminacijskom funkcijom vidljivo je kako ispitanici eksperimentalne grupe postižu bolje rezultate u svim elementima tehnike jedrenja, osim na varijabli letanje - flok $(-0,07)$ gdje ispitanici kontrolne grupe imaju nešto bolji prosječni rezultat. Najveću projekciju na diskriminacijsku funkciju ima varijabla prihvaćanje - glavno jedro $(0,51)$, zatim slijede prihvaćanje - kormilo $(0,43)$ kruženje - kormilo $(0,40)$, opadanje - kormilo $(0,37)$ i prihvaćanje - flok $(0,3)$ dok ostale varijable imaju korelaciju sa diskriminacijskom funkcijom manju od 0,3 .

\section{DISKUSIJA}

Najveći problem kod polaznika osnovne škole jedrenja je dezorijentiranost u prostoru, koja je najviše otežana nerazvijenim osjećajem za smjer puhanja vjetra. Kao što se zna, vjetar se ne vidi, već ga se mora osjetiti, a taj se problem povećava kada je vjetar slabiji (Pluijms, Cañal-Bruland, Bergmann Tiest, Mulder i Savelsbergh, 2015), što je slučaj kod naših ispitanika a i većine početnika. Budući su u jedrenju uvjeti na pojedinoj jedriličarskoj poziciji potpuno različiti (Allen i De Jong, 2006), za očekivati je da će se pojedini studenti bolje snaći na određenim pozicijama na brodu u odnosu na druge. Iz dugogodišnje nastavne prakse uočena je veća težina prilagođavanja početnika na poziciju kormilara nego na pozicije glavnog jedra i floka, što logično proizlazi iz gore navedenog razloga slabe orijentacije, budući je upravo kormilar taj koji upravlja brodom i ima najveću odgovornost, dok ga flokist i onaj na glavnom jedru slijede i prilagođavaju jedra njegovom smjeru plovidbe. Iz istog razloga, element kao što je prihvaćanje početnicima stvara velike probleme zbog određivanja granice do koje se može kretati uz vjetar. Također je dokazano da se na svakoj jedriličarskoj regati dvije trećine ukupnog vremena provedu u jedrenju uz vjetar (Callewaert, Boone, Celle, De Clercq i Bourgois, 2014), puno drugačije nije ni za vrijeme učenja jedrenja, što početnicima zasigurno uvelike otežava koncentraciju. Zanimljivo je uočiti kako dobiveni rezultati u kontrolnoj grupi pokazuju očekivanu težinu pozicija na brodu (kormilar, gl. jedro, flokista). Ovi su rezultati naročito interesantni u usporedbi s eksperimentalnom grupom u kojoj su ispitanici bili podvrgnuti poduci uz pomoć poligona plutača, te se taj odnos prosječnih ocjena potpuno izmijenio pa su najviši rezultati postignuti na elementu prihvaćanje na pozicijama glavnog jedra i kormila (Tablica 1). Tako da su najveće razlike između ove dvije grupe u aritmetičkim sredinama prisutne kod elemenata prihvaćanje - glavno jedro (0.39), prihvaćanje - kormilo $(0.37)$ i kruženje - kormilo $(0,34)$. Univarijatna analiza varijance potvrdila je da su razlike između dvije grupe na ove tri varijable značajne na nivou značajnosti $\mathrm{p}=0,05$, te ukazala da se dvije grupe statistički značajno razlikuju i na varijablama letanje - kormilo i prihvaćanje - flok. Diskriminacijskom analizom utvrđena je značajna razlika (razina značajnosti $\chi 2$ testa manja od 0,01 ) u izvedbi jedriličarske tehnike između kontrolne i eksperimentalne grupe (Tablica 2), u korist eksperimentalne grupe koja se nalazi na pozitivnom polu diskriminativne funkcije (Tablica 4). Korelacije varijabli sa diskriminativnom funkcijom (Tablica 3) potvrdile su rezultate univarijatne analize varijance i pokazale da pet navedenih varijabli ima najveću projekciju na diskriminativnu funkciju i da upravo one čine najveću razliku između ove dvije skupine ispitanika.

$\mathrm{Na}$ osnovu dobivenih rezultata možemo zaključiti kako je eksperimentalna grupa superiornija od kontrolne, pogotovo na zahtjevnijim elementima tehnike jedrenja kao što je prihvaćanje i zahtjevnijoj poziciji kormilara, te sa sigurnošću možemo tvrditi da su ovakvi rezultati posljedica primjene poligona plutača. Sa perceptivnog stajališta, jedrenje je sport koji

Prlenda, N., Oreb, I., \& Vujčić, D. (2018). Plutača kao pomagalo u poduci osnovnih elemenata jedrenja. Sportlogia, 14 (1), 47-55. doi: 10.5550/sgia.181401.se.pov 
zahtijeva visoku razinu percepcije vizualnih poticaja (Manzanares, Menayo, Segado, Salmeron i Cano, 2015). Najvažnija uloga poligona plutača je pomoć u shvaćanju jedriličarskog prostora kod početnika, te olakšanje u orijentaciji prema vjetru (Oreb, 2000). Inteligencija i pažnja temelj su učenja (Alexandru i Gloria, 2015), upotrebom plutača omogućujemo početniku bolje obrača pažnju i da se koncentrira na osnovne manevre prilikom upravljanja plovilom ili prilikom ugađanja jedrilja. Najveći problem kod polaznika osnovne škole jedrenja kao što smo već naveli je dezorijentiranost u prostoru te vjerujemo kako se upravo taj problem izražava u kontrolnoj grupi, te možemo zaključiti kako je poligon plutača kod eksperimentalne grupe uspio smanjiti zbrku u glavi ispitanika koja nastaje zbog gubitka prostorne orijentacije, te se najviše odražava na kormilaru o kojem ovisi prilagođavanje kuta plovila u odnosu na vjetar. Također, može se pretpostaviti da je pomoću poligona plutača postignuta i puno veća zainteresiranost ispitanika za provođenje vježbi tijekom poduke.

Rezultate dobivene ovim istraživanjem teško je usporediti s postojećim saznanjima. Naime, iako se u posljednja dva desetljeća osjetno povećao i broj znanstvenih istraživanja u jedrenju (Felici, Rodio, Madaffari, Ercolani i Marchetti, 1999), malobrojne činjenice usmjeravaju prema istraživanjima koja bi iznjedrila optimalne metodičke postupke i pomagala, te ubrzala proces poduke i učenja jedriličarskih vještina. Jedno od rijetkih istraživanja proveo je Oreb (1984), doduše u srodnom sportu, jedrenju na dasci, gdje se sintetička metoda učenja pokazuje superiornijom od analitičke. Gotovo trideset godina kasnije u svojoj doktorskoj disertaciji Prlenda (2012) se bavi učinkovitosti različitih modela poduke jedrenja na dasci. Njegovo istraživanje donekle je u suglasnosti sa ovim. Naime, iako u tom istraživanju ispitanici eksperimentalne grupe s primjenom poligona plutača pokazuju više prosječne ocjene od ispitanika kontrolne grupe, te razlike nisu bile statistički značajne. Autor ovo objašnjava činjenicom da u prvim danima, kada student ostvaruje prve korake na dasci, može više biti usredotočen na zadatak da ne izađe iz označenog koridora (poligona) nego što je koncentriran na izvođenje zadanog elementa, te $u$ tom trenutku poligon plutača kod pojedinca može postati remeteći faktor, a ne pomoć. Isto tako uvjeren je kako značaj poligona plutača raste s napredovanjem studenta i kako bi uloga poligona došla do punog izražaja u daljnjem tijeku poduke.

Iako su navedena istraživanja provedena na srodnom sportu, ipak se radi o potpuno drugačijim strukturama gibanja, te ni ne čudi da rezultati nisu u potpunosti suglasni. Zaključno, dobiveni rezultati upućuju na primjenjivost poligona plutača u poduci kormilara početnika osobito kod zahtjevnijih elemenata tehnike kao što je prihvaćanje u jedrenju. Iako se napredak dogodio i kod drugih elemenata, nije bio dovoljno velik te ga ne možemo smatrati značajnim. Ovakvi rezultati olakšat će nam buduće planiranje i programiranje, te u konačnici i samu provedbu škola jedrenja, što će dodatno ubrzati proces podučavanja. Nadalje, postavljanje plutača (poligona) u podnebljima gdje nam je za to potrebno duže vrijeme, primjerice zbog velikih dubina postavljat će se samo prilikom učenja zahtjevnijih elemenata (prihvaćanje, itd.).

\section{ZAKLJUČAK}

Istraživanje je provedeno na dvije grupe ispitanika (eksperimentalna i kontrolna) na kojima su primijenjena dva različita metodička pristupa u poduci jedriličarskih vještina. Jedna grupa (kontrolna) bila je podvrgnuta standardnom pristupu rada bez upotrebe poligona plutača kao pomagala dok je druga grupa (eksperimentalna) obučavana isključivo pomoću zadataka u poligonu plutača. Bitno je napomenuti kako su se ispitanici prvi put susreli s jedrenjem.

Uzimajući u obzir sve analizirane rezultate moguće je zaključiti kako je poligon plutača kao metodičko pomagalo imalo značajan utjecaj na količinu usvojenog znanja jedriličarskih vještina. Također, na osnovu dobivenih rezultata možemo zaključiti kako

Prlenda, N., Oreb, I., \& Vujčić, D. (2018). Plutača kao pomagalo u poduci osnovnih elemenata jedrenja. Sportlogia, 14 (1), 47-55. doi: 10.5550/sgia.181401.se.pov 
poligon plutača najviše utječe na brzinu usvajanja najzahtjevnijih elemenata za početnika kao što je prihvaćanje. Samim time u početnom djelu škole jedrenja možemo izostaviti takve poligone (zbog otežanih uvjeta kod postavljanja takvih poligona u svrhu manjeg gubljenja vremena) te ih postavljati samo u danima kada se savladavaju najsloženiji elementi. Valja napomenuti kako su ove dvije grupe radile u idealnim uvjetima u kojima je vjetar bio konstantno između 4 i 6 čvorova te je more zbog okruženosti otocima također bilo mirno ili malo valovito. Iz navedenih razloga nameće se pitanje bi li ovakvi rezultati koji idu u korist modela s primjenom plutača bili još izraženiji u situaciji otvorenog mora (strah prema nepoznatom, valovi itd.) ili bi snažniji vjetar olakšao orijentaciju, a samim time i smanjio razlike između ovih dviju grupa.

\section{LITERATURA}

Alexandru, M.A., \& Gloria, R. B. (2015). Intelligence influence in beginner student learning of sailing. Journal of Physical Education and Sport, 15(1), 114-119. https://doi.org/10.7752/jpes.2015.01019

Allen, J. B., \& De Jong, M. R. (2006). Sailing and sports medicine: A literature review. Commentary. British Journal of Sports Medicine, 40(7), 587-593.

https://doi.org/10.1136/bjsm.2002.001669

PMid:16547146 PMCid:PMC2653898

Bøymo-Having L.A, Grävare M.B., Silbernagel K.G. (2013). A prospective study on dinghy sailors training habits and injury incidence with a comparison between elite sailor and club sailor during a 12-month period. British Journal of Sports Medicine, 47(13), 826831.

https://doi.org/10.1136/bjsports-2012-091841

PMid:23673519

Callewaert, M., Boone, J., Celle, B., De Clercq, D. \& Bourgois, J.G. (2014). Cardiorespiratory and Muscular Responses to Simulated Upwind Sailing Exercise in Optimist Sailors. Pediatric Exercise Science, 26, 56-63. https://doi.org/10.2165/00007256-200939020-00003

Felici, F., Rodio, A., Madaffari, A., Ercolani, L., \& Marchetti, M. (1999). The cardiovascular work of competitive dinghy sailing. Journal of Sports Medicine and Physical Fitness, 39(4), 309-314. https://doi.org/10.1080/17461391.2014.963690

Manzanares, A., Menayo, R., Segado F., Salmeron, D. \& Cano, J.A. (2015). A probabilistic model for analysing the effect of performance levels on visual behaviour patterns of young sailors in simulated navigation. European Journal of Sport Science, 15(3), 203212.

https://doi.org/10.1080/17461391.2014.963690

PMid:25296294

Mejovšek, M. (2003). Uvod u metode znanstvenog istraživanja. Jastrebarsko, RH: Naklada Slap.

Neville, V., \& Folland, J. P. (2009). The epidemiology and aetiology of injuries in sailing. Sports Medicine, 39(2), 129-145.

https://doi.org/10.2165/00007256-200939020-00003

PMid:19203134

Oreb, G. (1984). Efekti primjene analitičkog i sintetičkog pristupa u obučavanju jedrenja na dasci. Kineziologija, 16(2), 185-192.

Prlenda, N., Oreb, I., \& Vujčić, D. (2018). Plutača kao pomagalo u poduci osnovnih elemenata jedrenja. Sportlogia, 14 (1), 47-55. doi: 10.5550/sgia.181401.se.pov 
Oreb, G. (2000). „Hodnik“ plutača - jedriličarska igraonica. In M. Andrijašević (Eds.), Zbornik radova Znanstveno - stručnog savjetovanja „Slobodno vrijeme i igra“, $u$ sklopu 9. Zagrebačkog sajma sporta i nautike, (pp. 138-141). Zagreb, RH: Fakultet za fizičku kulturu, Sveučilišta u Zagrebu.

Pluijms, J.P., Cañal-Bruland, R., Bergmann Tiest, W.M., Mulder, F.A. \& Savelsbergh, G.J.P. (2015). Expertise effects in cutaneous wind perception. Atten Percept Psychophys, 77, 2121-2133.

https://doi.org/10.3758/s13414-015-0893-6

PMid:25896122 PMCid:PMC4521093

Prlenda, N. (2012). Učinkovitost različitih modela poduke jedrenja na dasci. Doktorski rad. Kineziološki fakultet, Sveučilišta u Zagrebu.

White, R., \& Wells, M. (1995). Race training - Great Britain

\section{SUMMARY}

The aim of the research is to determine efficiency of buoys as a methodic tool in teaching and learning of basic elements of sailing. Analyzed sailing elements were heading up, tacking, bearing away and jibing on three different sailing positions (helm, main sail and jib). The research was carried out on the sample of 178 Kinesiology faculty students, divided into two groups (control group and experimental group). The experimental group examinees were subjected to teaching using various buoy ranges, while control group examinees were subjected to classic teaching methods (without buoy range). The teaching process was carried out during seven days period on Elan 19 sailboats. Teaching and evaluation of sailing elements was conducted by teachers with long experience in teaching of sailing. By means of descriptive statistics the difference in amount of acquired knowledge using two different models of teaching of sailing skills was determined. The results of descriptive statistics show higher score for examinees of experimental group in almost all elements of sailing technique, except in element tacking-jib. One-way analysis of variance showed that those differences are significant on the position helmsman in elements heading up, bearing away and jibbing, on the position mainsail, in the element heading up and also on the jib position, element heading up. Through further analysis, a discriminant analysis confirmed significant difference in the amount of acquired knowledge of sailing technique between two analyzed groups $(\chi 2=47,73$, $p=0,00)$. Finally, the authors conclude that buoy range had significant influence on the amount of acquired knowledge of sailing skills.

Key words: buoy range, teaching methods, sailor, sailing school, beginner

Primljeno: 19.04.2018.

Odobreno: 02.06.2018.

Korespodencija:

Danijela Vujčić,

prof., student poslijediplomskog doktorskog studija, danijela.vujcic@kif.hr danijelakostanic@gmail.com

Prlenda, N., Oreb, I., \& Vujčić, D. (2018). Plutača kao pomagalo u poduci osnovnih elemenata jedrenja. Sportlogia, 14 (1), 47-55. doi: 10.5550/sgia.181401.se.pov 